\title{
Integrating Critical Thinking Skills in Higher Education
}

\author{
Dr. Maya Bazhouni (Corresponding author) \\ Department of English Language, Lebanese University, Lebanon \\ PO Box: 966 Tripoli, Lebanon \\ Tel: 00961-318-0901Ｅ-mail: mayabchidiac@gmail.com
}

Received: February 20, 2018 Accepted: April 5, 2018 Published: April 7, 2018

doi:10.5296/elr.v4i1.12964

URL: http://doi.org/10.5296/elr.v4i1.12964

\begin{abstract}
Critical thinking is an essential topic in the education system. Additionally, it has evolved into a buzzword in many schools and educational institutions. Over the years, researchers have attempted to define what critical thinking is all about and its significance in the education sector. Available research evidence shows that critical thinking goes beyond the memorizing of information. Instead, it requires students to carefully analyze and evaluate information and weigh the implications of their choices before making a decision. This paper aimed at exploring ways of promoting critical thinking among college students. Using an exploratory design and secondary data, the study revealed that educators have a key role to play in promoting critical thinking among learners. In particular, teachers can use questioning, proper classroom arrangement, written assignments, and classroom debates and discussions to promote critical thinking among college students.
\end{abstract}

Keywords: Critical thinking, Education, Skills, Decisions

\section{Introduction}

Students are usually called upon to make vital decisions and develop solutions to the various challenges that they face in life. Thus, they are required to develop good critical thinking skills and apply them to the different problems that they may face in the course of their education. Bishop (2013) posits that an excellent critical thinker is able to use various and appropriate reasoning skills to analyze and solve a situation in the learning environment. However, the author cautions that critical thinking is a skill that does not come naturally. Therefore, students should develop qualities that will help them to become good critical thinkers. In addition, teachers need to play an instrumental role in helping learners to acquire and develop their critical thinking skills (Stein \& Haynes, 2011; Bishop, 2013). Stein and Haynes (2011) noted that the process of becoming a critical thinker entails minimizing systematic errors that can lead to misinformed and wrong decisions and actions. Stein and Haynes (2011) further noted that the first step in avoiding systematic errors is to eliminate 
quantitative, automatic, and logical biases that may lead to wrong decisions. Bishop (2013) concurs by stating that critical thinking is regarded as one of the most important outcomes of graduate education. Despite this being the case, many undergraduate students tend to lack these important skills in life. Moreover, such students often show shortcoming and limitations as they act and interact with other people. Due to the systematic and pervasive human shortcomings when it comes to critical thinking, researchers and scholars from several disciplines have taken it upon themselves to analyze and study critical thinking. Additionally, the researchers have tried to define the concept and identify ways through which it can be improved among students.

In the learning context, critical thinking is viewed as a method that can help students to make wise decisions and solve different problems related to their academic and personal lives. Furthermore, it is considered to be a skill that can help students to improve their academic performance and become useful members of the society. However, critical thinking does not always guarantee successful outcomes among students since it can limit students by providing a framework and pathway that can help in improving decisions.

Researchers contend that decisions that are made using the best available critical reasoning methods and procedures may still fail to succeed. Thus, the chances and risks of failure even in such cases cannot be overlooked. For colleges and universities to improve critical thinking among students, they must focus on a wide range of elements that influence how students think and address various problems that they face. In particular, the process entails embracing teaching methods that will help students to improve their critical reasoning and thinking skills. Also, educators must work hard to diagnose and analyze the problems that may prevent students from being good critical thinkers. From an administrative perspective, the role of resource availability and support in developing successful interventions to enable students to gain critical thinking skills cannot be overlooked. Thus, universities and college administrators must show full commitment to the initiatives taken by teachers to train students and help them to improve their critical thinking skills. Besides, they must enable teachers to come up with models that can be used to improve the skills of leaders and enable them to approach various academic and personal problems from a critical perspective. This way, all the main stakeholders in the education system can work together for the benefit of the students. In addition, the move may enable students to benefit from critical thinking and develop skills that will enhance the quality and nature of their decisions. The purpose of this paper is to examine how to promote critical thinking skills among college students. At this level, what are some of the strategies that should be developed in order to promote better critical thinking skills among college students?

\section{Problem Statement}

Students face a wide range of academic and personal problems and challenges that may affect their lives in different ways. From time to time, they are expected to make prudent decisions and come up with appropriate solutions to the problems that they may face in life and school. However, not every student is a critical thinker. Furthermore, some students may lack the skills and capabilities required to think critically and to address the academic and personal problems that they face. There is a wide range of reasons that can lead to the lack of critical thinking skills and abilities. For instance, inherent human weaknesses and lack of 
understanding of what critical thinking entails may make it impossible for students to acquire the necessary skills. Such students show weaknesses and biases that lead to wrong and erratic decisions. Thus, students need to learn about critical thinking so that they can understand its significance and identify ways through which they can improve their capabilities and skills. In other cases, lack of critical thinking skills has been attributed to wrong human judgment during uncertainty. According to Kahneman (2011), available research evidence shows that human beings make common and significant thinking errors and mistakes. Also, these errors tend to be predictable, systematic, and unconscious. In other cases, they appear to be ingrained in the manner in which individuals have evolved to be a machinery of cognition. Hastie and Dawes (2010) concur by stating that human beings may fail to think critically because of their systematic errors and biases. These errors hinder them from analyzing a situation logically and qualitatively to come up with the best solution to a problem.

While discussing the issue of critical thinking in the context of the college education, some researchers have argued that many students tend to jump to conclusions with little or no evidence to support their choices and actions. In other words, the amount and quality of evidence available in a situation do not influence the decisions that some students make. Those who do not base their decisions on high-quality evidence struggle to make the right decision and may find life to be more challenging compared to the rest of students (Hallinan, 2009). Kahnema (2011) explains the heuristic approach to problem solving which hinders critical thinking. One of the factors that the author identifies is the tendency of people to predict the frequency of a given situation or event on the basis of the examples that are in their mind.

While it is widely accepted that human beings may lack critical thinking skills, it is also a known fact that it is important for students to develop such capabilities and traits. Researchers contend that critical thinking remains one of the most important skills that student can learn in college (Hart, 2013; Kahnema, 2011). Furthermore, available research evidence shows that students can be able to complete their education and successfully join the workforce when they have superior critical thinking skills and abilities (Hart, 2013). In particular, it has been reported that students who show the skills and capacity to think in a critical way will be better placed to solve complex problems and communicate in a clear manner. In this context, critical thinking is regarded as a skill that can help students to improve their academic performance while also preparing them for the workforce. In fact, such skills may determine whether students will be able to use the knowledge and understanding that they have acquired from school to improve their lives and the well-being of the society as a whole.

Other researchers have argued that critical thinking skills are important because they allow students to confront the realities of modern life. According to Stein et al. (2010), the modern life is characterized by the existence of a wide array of problems that require proper thinking and understanding. Moreover, people are faced with overwhelming problems that may require them to examine the needs of various competing groups. The ability of students to evaluate the available information and use the findings to make prudent decisions can enable human beings to live a successful life. Thus, critical thinking ability is viewed as something that can lead to excellent decisions. On the other hand, lack of critical thinking skills is 


\section{MInstitute Macrothink $_{\text {Int }}$}

viewed as a trend that can result in poor decisions in the society and learning environment (Hastie \& Dawes, 2010). The poor decisions may have negative consequences on the decision maker and the society as a whole. Thus, an effort must always be made to identify students who are not critical thinkers and help them to acquire such skills. This way, teachers will be able to prepare students to succeed in their personal and academic life.

\section{Methodology}

As stated earlier, the current study seeks to explore ways of promoting critical thinking among college students. The issue of critical thinking among college students is a wide and important topic that has attracted the attention of researchers. Thus, it was imperative to come up with a clear research methodology that would be used to achieve the set goals and objectives. A review of existing research methods in the literature revealed that the most appropriate research design for this study was the exploratory research. According to Shields and Rangarajan (2013), exploratory research is usually carried out to establish priorities, improve existing research designs, and to develop operational definitions in a topic of interest. This particular method of research can help explore a particular topic and provide important insights to develop conclusions and identify areas for further investigations. When one of the primary purposes of research is to gather insights and develop familiarity with an area of interest, the exploratory design comes in handy. In the current study, the exploratory design was suitable as it could be used to gain experience and develop a deep understanding of the way in which critical thinking can be promoted among college students.

Like any other methodology, Shields and Rangarajan (2013) explain that the exploratory design has some advantages and disadvantages that needed to be taken into account in the present study. One of the primary advantages of exploratory research is that it provides an avenue through which the researcher can gain a deep understanding of a topic or issue of interest. In other words, the design allows the researcher to gather data from a wide array of sources that relate to the topic of study. Secondly, the design can be used to conduct concept testing. In this case, the researcher conducts the exploratory work to check the concept before subjecting it to further investigations and research. Third, the exploratory research is flexible. This design uses various techniques such as qualitative research, secondary research, and quantitative methods to gather information needed to answer research questions. Finally, exploratory design can be used to gather vital insights that can inform future research. These advantages make the design suitable for examining ways of improving critical thinking among college students.

There are, however, certain shortcomings of exploratory research that were taken into account in the course of the current study to improve the validity and reliability of the results. One of the main disadvantages of the method is that the results from such studies may not be conclusive. Besides, the data collected may lack statistical strength since it is not always subjected to statistical analysis. Secondly, the reliance on information and data from previous studies means that exploratory studies may not provide primary insights into a topic of interest. Thus, generalizing the findings to a larger population may not be an easy process. Third, the studies are susceptible to bias as the researcher is expected to review available information and use it as the basis for studying and exploring the topic of interest. Finally, exploratory studies rely on modest samples to explore a subject. Thus, the results may not be 
generalized to a larger population. The aforementioned shortcomings of exploratory research may affect the quality and validity of the findings of a study. In the present case, however, the researcher strived to remain objective and gather high-quality data that could help in determining how critical thinking can be improved among college students. Also, an attempt was made to reduce bias and errors in the course of the study by being objective during the data collection, analysis, and interpretation processes.

In the present study, the data was gathered through a secondary research technique. Secondary research entails summarizing and synthesizing existing research evidence rather than conducting primary research. In other words, the researcher relies on existing results from previous studies instead of carrying out primary research to gather empirical data. In this regard, secondary research comes out as a technique that relies on information and data that has been compiled, analyzed, organized and published by other researchers. The information used in such studies are obtained from a wide range of sources that include studies and reports by trade associations, business, government agencies, and individual researchers. In this study, data on critical thinking among college students was obtained from books, previous studies, journals, newspapers, peer reviewed documents, and government reports.

Like any other data collection technique, the secondary method has some advantages that influenced its use in the current study. The first advantage is that secondary research saves time as the researcher does not have to go to the field to gather primary data and information on the topic of study. Instead, the researcher focuses on locating and analyzing existing information and data that can help answer the research question. Secondly, secondary research allows the researcher to rely on a wide range of sources to collect data and explore the topic of study (Denscombe, 2010). This way, the researcher is better placed to come up with a multi-perspective understanding of the phenomenon under investigation. Third, this technique reduces the cost of the study, as it does not require the collection of primary data. Finally, the use of secondary research method helps generate new insights from existing studies. In other words, the researcher is able to analyze existing data to identify gaps that can be used as the basis for future studies. In this study, the researcher analyzed the sources to ensure that high-quality data was gathered and used to explore ways of improving and promoting critical thinking among college students.

The other critical process in the methodology that was used in the current study was data analysis. As stated earlier, the researcher relied on information published in journal articles, books, and government reports to explore the topic of study. The information was analyzed through the thematic analysis process. The underlying idea was the identification of the major and primary themes related to the topic of the study by examining the way different researchers have approached it. The goal was to identify the vital areas that previous studies had scrutinized as they strived to appreciate and explore critical thinking.

\section{Literature Review}

The concept of critical thinking has featured significantly in college education literature and studies. The interest is partly attributed to the realization that critical thinking is important in college education. Furthermore, researchers appear to have been motivated by the results of previous studies that indicated that critical thinking could influence academic outcomes and 
performance of college students (Stein \& Haynes, 2011). Additionally, attempts have been made to examine what critical thinking entails, its effects on academic success, and the manner in which it can be improved and promoted among students. Thus, a review of these studies provides a basis and foundation for achieving the objectives of the current study.

One of the areas that researchers have focused on is the definition of critical thinking. A review of existing research literature reveals that researchers have taken different approaches and routes to define critical thinking in the context of education. In particular, the existing literature reveals that critical thinking tends to have a wide range of meaning to various people. In most cases, the meaning will depend on the context of debate and discussion. According to Walker (2014), critical thinking refers to "the intellectually disciplined process of actively and skillfully conceptualizing, applying, analyzing, synthesizing, and/or evaluating information gathered from, or generated by, observation, experience, reflection, reasoning, or communication, as a guide to belief and action" (p. 44). The author goes on to state that critical thinking often comes out as an exemplary form that is based on intellectual values such as clarity, precision, sound evidence, depth, consistency, fairness, and breadth. The Association of the American Colleges and Universities, on the other hand, came up with a value rubric to describe and promote critical thinking among students. In this case, critical thinking is described as the mental habit that is characterized by the in-depth exploration of ideas, artifacts, and issues before coming up with a conclusion or opinion. Thus, critical thinking involves understanding an issue, analyzing it, looking at different sides, weighing the implications of every choice, and relying on research evidence to make a sound decision (Bishop, 2013).

According to Bishop (2013), critical thinking is a very broad concept that has attracted a wide range of definitions. Moreover, the author noted that the broadness of the concept has made it difficult for researchers to reach a consensus on its definition. Bishop (2013) posits that many researchers contend that critical thinking entail applying good reasoning skills and strategies to find a solution to a problem. Hastie and Dawes (2010) assume that the critical reasoning goes through five major stages. The first stage is the definition of the problem at hand in a correct way. In this phase, the decision maker should strive to understand the problem and its potential implications. The second stage is the determination of the appropriate and accurate information that can be used in making the right decision. The third stage is the evaluation of the significance and the quality of the available information that can be used in the decision-making process. The fourth stage is the process of using the available information and evidence to solve the problem and make a good decision. The final state entails evaluating the entire process with the goal of improving it and managing any adverse effects. While explaining the process of critical thinking, Hastie and Dawes (2010) noted that critical thinking requires students to show good reasoning and rational decision-making skills. Besides, the author argues that the process requires the decision maker to follow the rules of rational thinking and logic while also using high-quality data and information to make a successful decision.

The varied definitions of critical thinking are very challenging. The first one is that there is no universal definition of the concept of critical thinking. Secondly, some frameworks and definitions use polar opposites (i.e., specifists and generalists) to describe critical thinking. 


\section{MInstitute Macrothink $_{\text {Int }}$}

Despite these differences, available evidence shows that there are some aspects that tend to overlap in the models and approaches that researchers use to define and explore critical thinking. The first area is that for an individual to think in a critical way, he or she must be in a position to process and analyze new information without the influence of prior beliefs (Papastephanou \& Angeli, 2007). The process entails suspending and overlooking the biases that are shaped and initiated by previous experiences. These biases are usually inherent in the choices that human beings make from time to time. Thus, suspending them tends to counter the manner in which human beings think. Also, it requires the total repudiation of past experiences and reliance on the current information and data when making decisions.

According to West, Toplak, and Stanovich (2008), critical thinking can only be achieved when an individual gives up the influence of prior beliefs. Furthermore, a person must strive to reason in a logical way and avoid trying to match current decisions with past beliefs. This way, he or she will be able to achieve non-egocentric processing of information and data during the decision-making process. Noone, Bunting, and Hogan (2015) identified the need to engage in purposive, well-reasoned and reflective thinking as the other area of convergence in the definitions that exist in previous studies. The authors argued that critical thinking is a complex concept that should not be limited to a narrow construct. Despite this being the case, available evidence shows that it is a construct that is integrative, consisting of salient elements related to reflective, well-reasoned, and purposive thinking. The overall goal is to achieve the non-egocentric processing of information to reach a well-reasoned judgment and decision in the long run.

Critical thinking remains one of the most valuable skills that students learn in the course of their college education. A survey carried out by Hart Research Associates (2013) showed that critical thinkers are able to solve a wide range of problems to communicate their ideas in a clear manner. They are even able to work in teams to achieve common goals and solve common problems. It is for this reason that researchers argue that college students require critical thinking skills to succeed in school and to achieve a successfully transition into the workforce (Hart Research Associates, 2013). College education is not only about acquiring facts and specific skills. Instead, it is a level of education in which students gather experience that will help them in their future lives. Additionally, it provides an important opportunity for students to improve their thinking and problem solving skills. As students learn about their courses and problems from different disciplines, they are also expected to improve their reasoning and thinking skills so as to survive in the dynamic and highly competitive professional world (Hart Research Associates, 2013). Thus, students who end up with their degrees without getting critical thinking skills should feel shortchanged. Also, their teachers should know that they may have failed in preparing students to face the outside world and succeed in their careers.

Critical thinking remains one of the most researched and discussed high order skills in the context of the college education. Besides, it is viewed as a skill that plays a key role in decision making, problem-solving and logical thinking processes (Butler, 2012). Liu, Frankel, and Roohr (2014) argue that critical thinking is a contentious skill in research circles due to its high degree of generality and the practical impact on academic achievement, personal life choices, and professional life. This topic continues to attract the heightened attention of 
policymakers and educators in the context of the college education. Moreover, it has been included as one of the critical and core learning outcomes of college students in several universities around the world. A recent survey carried out by the Association of American Colleges and Universities (2011) reported that 95 percent of academic officers from a total of 433 institutions of higher learning viewed critical thinking as one of the fundamental skills that college students should develop in order to succeed in the workforce. The results support those from an earlier study carried out by Casner-Lotto and Barrington (2006). In that case, $92.1 \%$ of employees who took part in the survey stated that lack of critical thinking skills is one of the reasons why students fail to successfully adapt in the workforce (Casner-Lotto \& Barrington, 2006).

The significance of critical thinking was also underscored in another study carried out by the Educational Testing Service (2013). In this case, the researchers interviewed vice presidents and program directors from colleges and universities. The interviews concentrated on education skills and critical thinking. The results of the study showed that many educators consider critical thinking an important and valuable skill required for students to achieve professional and academic success. Markle et al. (2013) also highlighted the significance of critical thinking in college education. In particular, the author noted that students require critical thinking skills to achieve their full potential in schools and to smoothly enter the workforce without major challenges. Markle et al. (2013) went ahead to state that colleges and educators must identify ways and strategies that can be used to train students and help them to become critical thinkers. The process entails training students to understand a problem, analyze relevant information, weigh the implications of all the available options, and make the right and logical decision on the basis of available evidence.

Human beings take various paths as they develop from one stage to another. Furthermore, two individuals may experience the same input by developing different interpretations about them. Students may face different scenarios and interpret and act upon them in diverse ways. The differences stem from each individual's approach to make sense of the environment based on his/her experiences (Hart, 2013). The way in which people make meaning will have a significant effect on their ability to think in a critical manner. However, this should not be interpreted to imply that those who are at the low levels of meaning-making fail to think or lack the ability to make decisions. Instead, it implies that when people are making decisions, they tend to process information and data differently. From a constructivist point of view, the different approaches that individuals take when making decisions have unique pros and cons. Besides, researchers contend that the process can be influenced by personal experiences and biases. In the long run, it will have an effect on a person's ability to think critically.

Critical thinking has evolved to become a useful and valued construct in today's competitive and chaotic society. It is for this reason that researchers strive to look at the construct and analyze how it occurs. Others have attempted to examine the relationship between critical thinking, education, and leadership. The primary focus is on ways of improving critical thinking skills and abilities. Recently, some studies have investigated the relationship between critical thinking skills and the disposition to think in a critical way among various groups, including students (Walker, 2003; Nold, 2017). Many argue that for a person to develop critical thinking skill, the disposition to think in a critical way must be nurtured 
carefully. Thus, several attempts continue to be made to help students to gain the disposition to think critically and develop critical thinking skills.

Recent studies have gone ahead to identify the specific skills, affects, and attitudes that influence the ability to think critically (Nold, 2017). Walker (2003) noted that a person who thinks critically shows certain skills and dispositions that other people may lack. For instance, such people often show truth-seeking tendencies as they analyze information and make conclusions. Furthermore, they rely on a wide range of theories and opinions to carefully analyze an information and make a decision. In other cases, the research shows that students who think critically have the tendency to analyze, evaluate, and synthesize information during the decision-making process based on issue of interest (Walker, 2003). Thus, educators' duty is to empower such students to acquire the skills in order to become critical thinkers and enable them to succeed in their current and future endeavors. Ricketts and Rudd (2005) contributed to the debate by stating that critical thinking requires the ability and skill to combine purposive reasoning, knowledge, and careful analysis of various options and their implications. The authors noted that the process requires an introspective approach to address questions and solve problems that affect individuals and the society as a whole (Ricketts \& Rudd, 2005). Since students can produce positive course outcomes when they think critically, educators and other stakeholders in the education sector have a key role to play in helping them acquire the necessary skills and capabilities (Nold, 2017). The move will not only improve academic performance but also give students the ability to successfully achieve their goals.

As a result of aforementioned studies and researches, critical thinking as a skill should not be taken lightly in college. It should be instead reinforced and adopted by educators through different techniques in order to empower students and help them think and analyze critically.

\section{Results}

To promote better critical thinking skills and to have more engaged students in any classroom, educators can rely on certain techniques to create a more interactive environment during the learning process. Such techniques can be classified in four categories: (1) Questioning, (2) Classroom debates and discussions, (3) Appropriate classroom environment, and (4) Written assignments.

\subsection{Questioning}

The first method that can help improve critical thinking skills among college students is prompting or questioning. In particular, research shows that prompts motivate students to think about an issue or problem of interest and come up with a solution. Depending on the manner in which the teacher asks the question, the student will be motivated to use different critical thinking skills like recognition of assumptions, interpretation, synthesis, and analysis to arrive at a decision (Walker, 2003). Research shows that the thoughtful and appropriate use of questions tends to be an essential activity among experienced and effective teachers (Walker, 2003; Nold, 2017). The questions will determine the thoughts that will be put to them and determine how students will relate information taught in class to the real world. Researchers argue that teachers need to ask high-level cognitive questions to promote the evaluation as well as the synthesis of concepts and facts (Nold, 2017). High-level cognitive 
questions use phrases and words like "explain" and "describe" to promote high-level thinking and reasoning among learners. In particular, it will promote simple yet critical skills like complex thinking, evaluation, and knowledge.

The other question approach and technique that can promote critical thinking skills is Socratic questioning. Walker (2003) defines Socratic questioning as an approach that strives to deeply explore and probe the underlying meaning, positions, justifications, and lines of reasoning in a given context or problem. In this case, the educator asks questions that will allow and motivate students to examine diverse viewpoints, assumptions, and evidence (Walker, 2003). The methods focus on engaging students and motivating them to think. Walker (2003) goes on to point out that the Socratic method also focuses on clarification while the student's answer to questions can be followed by asking another student to summarize the answers given in a previous case. As the student summarizes the information provided by another student, the learner will demonstrate whether he or she was keen in class, listened to the other student, and is able to put it in his or her words. In some cases, Socratic questioning encourages educators to avoid questions with a single set of answers. This practice gives students an opportunity to listen to different viewpoints and compare the different approaches that can be used to tackle an issue. Moreover, this trend limits the number of wrong answers to a problem as it provides students with an opportunity to rely on their understanding and thoughts to come up with an appropriate answer to a problem (Walker, 2003; Nold, 2017). Regardless of the question or answer, the student must strive to think critically about the issue or topic and arrive at an appropriate conclusion (Walker, 2003). In this sense, a wide range of solutions to a problem will emerge, and students will have the chance to see how others approach the assigned problem.

It is imperative for educators to orient students to the unique type of classroom interactions that will take place in the course of learning. In other words, educators should use questions that will reflect on the kind of classroom interactions that they intend to promote (Markle et al., 2013). The process can entail using brief and proactive questions that promote reflection among students. In other instances, it is important for the teacher to promote wait time, planned silence, and question and answer sessions. The wait time gives students the chance to think and reflect on the interactions that are taking place in the classroom. Moreover, it allows them to synthesize and internalize knowledge and information that is taught. Other researchers have noted that the wait time enables students to think about and review the available possibilities that are related to a given issue or question (Nold, 2017). This way, students will be better placed to provide an appropriate answer to a question.

\subsection{Classroom Debates and Discussions}

Research shows that classroom debates and discussions can promote high-level reasoning and critical thinking skills. In addition, there is a wide range of techniques and methods that teachers can use to encourage classroom debates and discussions. One such method is the negotiation model when students face credible yet antagonistic arguments about a given topic or issue. In such cases, the students are challenged to face and deal with misunderstandings and tensions between two opposing viewpoints (Nold, 2017). It is the tension between the opposing arguments that will drive high-level cognitive reasoning and critical thinking among learners. There are various social issues that tend to be controversial and can help in 
promoting discussions and debates in classrooms where students may either oppose or support a given stand related to the topic at hand.

There are cases where teachers help students to acquire critical thinking skills by giving them an opportunity to talk about their reasoning processes. As noted earlier, people take different approaches and ways when analyzing or assessing information (Ricketts \& Rudd, 2005). In addition, some of the decisions and choices that people make can be influenced by personal beliefs and past experiences. When students are not able to avoid the biases associated with personal beliefs and past experiences, they may struggle to become critical thinkers and decision makers (Nelson \& Crow, 2014). Therefore, teachers need to give students a chance to understand their thinking process and determine how they can acquire critical thinking skills. For instance, educators can use a task that requires students to communicate clearly and accurately their reasoning and decision-making process. Moreover, the task should entail conducting the evaluation of the various reasoning and thinking approaches that they use in different contexts and settings (Nold, 2017). The advantage of this approach is that it enables students to understand their reasoning approach and that of other learners in the classroom. Secondly, the method provides an opportunity for students to evaluate their reasoning methods and determine whether it follows the critical thinking process (Ricketts \& Rudd, 2005). Finally, the intervention gives teachers the chance to educate students on the ways of becoming critical thinkers.

\subsection{Classroom Environment}

The classroom environment, as well as the setting in which the learning takes place, can determine how students can approach a particular problem and issue. During lessons, teachers can use examples that are in the classroom settings and those that students can easily relate to in order to generate a debate or discussion (Ricketts \& Rudd, 2005). The move will provide a forum for students to think about the issue at hand and share their views with the rest of the class. Irrespective of the topic of interest, the educator must urge students to think carefully about the topic and examine available information within and outside the classroom setting to reach a reasonable conclusion. As a result, students will not only get to learn about other people's perspectives, but also acquire critical thinking skills that will enable them to become professional thinkers.

Students and teachers share responsibility for the classroom environment and setting. In addition, research shows that the classroom environment can determine the learning approaches that teachers will use. There are certain environments that promote cooperative learning while others are suited for classroom discussions and project-based learning. Teachers have a duty to model students' thinking and support them to acquire critical thinking skills. In particular, they need to create a setting that will allow learners to approach ideas in a tentative manner and respect different viewpoints. According to Butler (2012), educators are required to create an atmosphere that promotes openness and inquiry where students can gather information, organize it, evaluate different options, and make valid conclusions. Besides, teachers should only monitor and interfere to provide guidance to students instead of focusing on evaluation and criticism of the decisions that students make from time to time. Also, the classroom environment should be designed in such a way that students feel that they are supported and challenged to think critically and independently (Nold, 2017). Thus, the 


\section{Macrothink}

teacher needs to pay attention to the manner in which students think and reason and encourage them to work on their investigative and communicative skills and abilities. Finally, any classroom arrangement should be done in such a way that allows learners to work together towards common learning and teaching goals.

\subsection{Written Assignments}

Other studies have reported that written assignments can also help in promoting and supporting critical thinking among college students. According to Walker (2003), both in and out of class assignments are essential methods to help students expand their understanding and thinking processes. In particular, it is noted that the decision to involve students in writing assignment serves students learning needs and promotes critical thinking because any writing process requires a wide range of attributes related to thinking and reasoning (Walker, 2003; Nold, 2017). As a result, the assignment will successfully encourage students to come up with logical and critical answers to the assigned prompt.

Teachers can rely on short and focused case studies to encourage and promote various aspects of critical thinking among students. The case studies can focus on a wide range of aspects of critical thinking such as evaluation, analysis, synthesis, and organization of information (Walker, 2003). For instance, students may be asked to write an assignment on how they would handle a given situation related to the subject or course of study. Such assignment requires the study to gather information, analyze it thoroughly, develop various alternatives, review the implications of every choice and make a final decision on the best course of action. Moreover, students will be exposed to their peers' answers and evaluate the process they have followed to reach the final decision (Walker, 2003). The variety of answers to the problems and assignment allow learners to defend their reasoning and answers to peers.

The written assignments can further provide excellent avenues for enriching student's knowledge and education while also allowing them to know how to apply critical thinking to real life situations. The primary goal of education is to prepare students to become useful members of the society and give them knowledge and skills that can help in addressing various challenges and problems in life (Walker, 2003; Kahnema, 2011). Teachers can decide to use real-life case studies and assignments as a tool to promote critical thinking.

Table 1 below shows a summary of the major methods that can be used to promote critical thinking among college students. 
Table 1. Ways of promoting critical thinking among college students

\begin{tabular}{|c|c|c|c|c|}
\hline Method & Questioning & $\begin{array}{l}\text { Classroom } \\
\text { Debates and } \\
\text { Discussion }\end{array}$ & $\begin{array}{c}\text { Classroom } \\
\text { Environment }\end{array}$ & $\begin{array}{c}\text { Written } \\
\text { Assignments }\end{array}$ \\
\hline Description & $\begin{array}{l}\text { The method } \\
\text { motivates } \\
\text { students to think } \\
\text { about an issue or } \\
\text { problem and } \\
\text { come up with a } \\
\text { solution. It also } \\
\text { promotes } \\
\text { high-level } \\
\text { cognitive } \\
\text { reasoning among } \\
\text { learners. }\end{array}$ & $\begin{array}{l}\text { Debates and } \\
\text { discussions } \\
\text { expose students } \\
\text { to credible yet } \\
\text { antagonistic } \\
\text { arguments about } \\
\text { a given topic or } \\
\text { issue. The } \\
\text { tension between } \\
\text { the different } \\
\text { arguments will } \\
\text { drive high-level } \\
\text { cognitive } \\
\text { reasoning and } \\
\text { critical thinking } \\
\text { among learners. }\end{array}$ & $\begin{array}{l}\text { Learning } \\
\text { environment and } \\
\text { current } \\
\text { classroom } \\
\text { content influence } \\
\text { student's } \\
\text { reasoning and } \\
\text { thinking. } \\
\text { Besides, the } \\
\text { method provides } \\
\text { a forum for } \\
\text { students to think } \\
\text { and share their } \\
\text { views with their } \\
\text { peers. }\end{array}$ & $\begin{array}{l}\text { In and out of } \\
\text { class assignments } \\
\text { are powerful } \\
\text { methods of } \\
\text { expanding and } \\
\text { supporting } \\
\text { student's } \\
\text { reasoning and } \\
\text { thinking. The use } \\
\text { of precise and } \\
\text { focused written } \\
\text { assignments can } \\
\text { help improve } \\
\text { specific aspects } \\
\text { of critical } \\
\text { reasoning among } \\
\text { students. }\end{array}$ \\
\hline
\end{tabular}

\section{Discussion}

The topic of critical thinking has featured significantly in education research and literature. In addition, it has always been one of the areas of focus among educators around the globe who consider critical thinking a skill that can help students to succeed in their academic journey and successfully step into the workforce. Thus, critical thinking continues to be an important topic for both primary and secondary research. A review of previous studies shows that defining critical thinking has been a challenging process. Researchers have come up with a wide range of definitions to demonstrate what critical thinking is all about and how it relates to different aspects of education such as the achievement of academic goals. Generally, researchers argue that critical thinking requires the thinker to evaluate, analyze, interpret, organize and synthesize information to make valid conclusions regarding a problem or issue of interest.

Researchers have further pointed out that critical decision making is important because it influences the approaches in which students make a wide range of decisions related to their education and personal life (Casner-Lotto \& Barrington, 2006). Unfortunately, not every student is a critical thinker or possess the skills that one needs to think critically. The results of the current study show that educators and stakeholders in the education sector can use a wide range of methods to promote critical thinking among college students. Even though teachers value students who think critically about concepts, the disposition and spirit to think critically is not always present among learners (Hallinan, 2009). It is also important to state 
that many departments and faculties expect students to think critically in any context. Others use lecture formats and teaching strategies that promote critical thinking among students. In classrooms, instructors strive to present and organize essential information in a way that will engage students and motivate them to think and reason critically (Casner-Lotto \& Barrington, 2006). Unfortunately, some instructional methods and teaching approaches make it impossible for students to give input in classrooms. In the long run, such practices eliminate the opportunity for learners to assess the information that is important to their goals and aspirations. The trend shows the need to identify and embrace methods that can promote critical thinking among students.

The current review shows that the process of promoting critical thinking skills among college students revolves around the teaching methods and strategies that educators use in any classroom setting. Researches show that students ought to be exposed to a wide array of teaching methods and approaches that promote critical thinking to be able to acquire as well as nurture critical thinking and reasoning skills. In some cases, students are intrigued and unable to come to a clear understanding of the problems they face in their classrooms (Casner-Lotto \& Barrington, 2006). These students need to get exposed to multiple perspectives and interpretations of any situation to stimulate purpose reasoning and growth. In the context of medical and nursing education which is a very critical field that requires hermeneutic approaches, for instance, students can move through clinical experience and develop critical thinking skills by witnessing various methods of managing a certain condition. Furthermore, an educator must use various and appropriate methods of teaching to help such students to understand the medical issue at hand and come up with an effective technique of dealing with it. Walker (2003) states that many educators often try to encourage students to acquire and learn a body of knowledge by presenting it in a lecture form. In addition, these educators expect students to internalize the knowledge when they get out of the classroom and apply it to the appropriate real-world setting (Hallinan, 2009; Kahnema, 2011). This technique should be eradicated and replaced by more valuable teaching methods and approaches that are required in this discipline or any other discipline to satisfy college students' needs and to provide them with enough guidance to think with a critical eye.

\section{Conclusion}

Critical thinking is one of the fundamental skills that college students should acquire to succeed in their academic and personal lives. In this context, researchers argue that educators have an important duty to identify and respond to the factors that may prevent students from thinking critically. In addition, educators have an active role to play in order to promote critical thinking among their students. The process entails encouraging students to ask questions, be inquisitive, and proactive individuals. In addition, teachers should strive to encourage students to gather, analyze, interpret, and evaluate available information to think critically and make evidence-based decisions. Methods such as questioning, appropriate classroom arrangement, written assignments, and classroom debates and discussions can help promote critical thinking and help students to acquire skills that will improve the quality of their current as well as future decisions and actions.

\section{References}

Association of American Colleges and Universities. (2011). The LEAP vision for learning: 
Outcomes, practices, impact, and employers' view. Washington, DC: Author.

Bishop, M. (2013). Thinking about critical thinking. Presentation, May 22, 2012, Florida State University.

Butler, H. A. (2012). Halpern critical thinking assessment predicts real-world outcomes of critical thinking. Applied Cognitive Psychology, 25(5), 721-729. https://doi.org/10.1002/acp.2851

Casner-Lotto, J., \& Barrington, L. (2006). Are they really ready to work? Employers' perspectives on the basic knowledge and applied skills of new entrants to the 21st century U.S. workforce. New York, NY: The Conference Board, Inc.

Denscombe, M. (2010). The good research guide: For small-scale social research projects. Open University Press.

Educational Testing Service. (2013). Quantitative market research [PowerPoint slides]. Princeton, NJ: Author.

Hallinan, J. T. (2009). Why we make mistakes. New York: Broadway Books.

Hart Research Associates. (2013). It takes more than a major: Employer priorities for college learning and student success. Association of American Colleges and Universities. Retrieved from http://www.aacu.org/leap/documents/2013_EmployerSurvey.pdf

Hastie, R., \& Dawes, R. M. (2010). Rational choice in an uncertain world (2nd ed.). Los Angeles, CA: SAGE.

Kahneman, D. (2011). Thinking fast and slow. New York: Farrar, Straus, and Giroux.

Liu, L., Frankel, L., \& Roohr, K. (2014). Assessing critical thinking in higher education: Current state and directions for next-generation assessment. Assessment \& Evaluation in Higher Education, 41(5), 677-694. https://doi.org/10.1080/02602938.2016.1168358

Nelson, L. P., \& Crow, M. L. (2014). Do active-learning strategies improve students' critical thinking? Higher Education Studies, 4(2), 77-90. https://doi.org/10.5539/hes.v4n2p77

Nold, H. (2017). Using critical thinking teaching methods to increase student success: An action research project. International Journal of Teaching and Learning in Higher Education, 29(1), 17-32.

Noone, C., Bunting, B., \& Hogan, M. J. (2015). Does mindfulness enhance critical thinking? Evidence for the mediating effects of executive functioning in the relationship between mindfulness and critical thinking. Frontiers in Psychology, 6, 2043.

Papastephanou, M., \& Angeli, C. (2007). Critical thinking beyond skill. Educational Philosophy and Theory, 39(6), 604-621. https://doi.org/10.1111/j.1469-5812.2007.00311.x

Ricketts, J. C., \& Rudd, R. D. (2005). Critical thinking skills of selected youth leaders: The efficacy of critical thinking dispositions, leadership, and academic performance. Journal of Agricultural Education, 46(1), 32-43. https://doi.org/10.5032/jae.2005.01032

Shields, P., \& Rangarajan, N. (2013). A playbook for research methods: Integrating conceptual frameworks and project management. Stillwater, OK: New Forums Press.

Stein, B., \& Haynes, A. (2011). Engaging faculty in the assessment and improvement of students' critical thinking using the CAT. Change: The Magazine of Higher Learning, 43(2), 44-49. https://doi.org/10.1080/00091383.2011.550254 


\section{Macrothink}

Education and Linguistics Research

ISSN 2377-1356 2018, Vol. 4, No. 1

Stein, B., Haynes, A., Redding, M., Harris, K., Tylka, M., \& Lisic, E. (2010). Faculty-driven assessment of critical thinking: National dissemination of the CAT instrument. Proceedings of the 2009 International Joint Conferences on Computing, Information, and Systems Sciences and Engineering, 2010. https://doi.org/10.1007/978-90-481-9151-2_10

Walker, R. (2014). Strategic management communication for leaders. Boston: Cengage Learning.

Walker, S. E. (2003). Active learning strategies to promote critical thinking. Journal of Athletic Training, 38(3), 263-267.

West, R. F., Toplak M. E., Stanovich K. E. (2008). Heuristics and biases as measures of critical thinking: associations with cognitive ability and thinking dispositions. J. Educ. Psychol., 100, 930-941. https://doi.org/10.1037/a0012842

\section{Copyright Disclaimer}

Copyright reserved by the author(s).

This article is an open-access article distributed under the terms and conditions of the Creative Commons Attribution license (http://creativecommons.org/licenses/by/3.0/). 